\title{
MICRODUREZA DE UMA RESINA COMPOSTA, COR INCISAL, POLIMERIZADA COM DIFERENTES FONTES DE LUZ
}

Giovana Mongruel GOMES; Osmara Maria Mongruel GOMES; João Carlos GOMES; Abraham Lincoln CALIXTO

Fontes de luz à base de LEDs têm sido lançadas no mercado odontológico. Avaliouse a microdureza de uma resina composta (Filtek Supreme-3MESPE/corYT-incisal) utilizando diferentes fontes de luz, sendo: Gl-Optilux401/Demetron (Halógena-grupo controle); GIIL.E.DemetronI/Demetron (LEDs) e GIII-EliparTMFreeLight ${ }^{\mathrm{TM} / 3 M E S P E ~(L E D s) . ~ C o n f e c c i o n o u-~}$ se cinco corpos-de-prova (CP) para cada grupo, em matrizes metálicas com $2 \mathrm{~mm}$ de espessura e $5 \mathrm{~mm}$ de diâmetro. A resina composta foi fotoativada por 40 segundos. Os CP foram armazenados à seco e na ausência de luz por 24horas. Em seguida, foi avaliada a microdureza I (Vickers) nas superfícies topo e base, através do microdurômetro digital HMV2 (Shimadzu) com carga de $50 \mathrm{gf}$, durante $30 \mathrm{~s}$. Os dados foram submetidos à Análise de Variância para dois critérios e Teste t Student. Os valores médios em HV apresentados na superfície topo por grupo foram: GI $(69,76 \pm 1,59)$; GII $(68,95 \pm 1,45)$ e GIII $(67,87 \pm 0,80)$, diferenças não significativas ( $p=0,119-A N O V A)$ e, para a superfície base os valores médios foram: GI $(62,73 \pm 1,57)$; GII $(62,21 \pm 0,65)$ e GIII $(61,06 \pm 0,87)$, diferenças não significativas $(p=0,086-A N O V A)$. Diferenças significativas ocorreram em todos os grupos entre as superfícies topo e as superfícies base $(p<0,001-t$ Student). Concluiu-se que não houve diferenças estatísticas entre as fontes de luz testadas, sendo que os valores das superfícies topo foram significantemente superiores aos observados nas superfícies base. 